Article

\title{
Evaluating Volatile Organic Compound Emissions from Cross-Laminated Timber Bonded with a Soy-Based Adhesive
}

\author{
Michael Yauk ${ }^{1}\left(\mathbb{D}\right.$, Jason Stenson ${ }^{1}$, Micah Donor ${ }^{2,3}{ }^{(D)}$ and Kevin Van Den Wymelenberg ${ }^{1,2, *}$ \\ 1 Energy Studies in Buildings Laboratory, Department of Architecture, University of Oregon, \\ Eugene, OR 97403, USA; myauk@uoregon.edu (M.Y.); jstenson@uoregon.edu (J.S.) \\ 2 Institute for Health in the Built Environment, University of Oregon, Eugene, OR 97403, USA; \\ mdonor@uoregon.edu \\ 3 Department of Chemistry, University of Oregon, Eugene, OR 97403, USA \\ * Correspondence: kevinvdw@uoregon.edu
}

Received: 2 September 2020; Accepted: 20 October 2020; Published: 22 October 2020

\begin{abstract}
Volatile organic compound (VOC) emissions from indoor sources are large determinants of the indoor air quality (IAQ) and occupant health. Cross-laminated timber (CLT) is a panelized engineered wood product often left exposed as an interior surface finish. As a certified structural building product, CLT is currently exempt from meeting VOC emission limits for composite wood products and confirming emissions through California Department of Public Health (CDPH) Standard Method testing. In this study, small chamber testing was conducted to evaluate VOC emissions from three laboratory-produced CLT samples: One bonded with a new soy-based cold-set adhesive; a second bonded with a commercially available polyurethane (PUR) adhesive; and the third assembled without adhesive using dowels. A fourth commercially-produced eight-month-old sample bonded with melamine formaldehyde (MF) adhesive was also tested. All four samples were produced with Douglas-fir. The test results for the three laboratory-produced samples demonstrated VOC emissions compliance with the reference standard. The commercially-produced and aged CLT sample bonded with MF adhesive did not meet the acceptance criterion for formaldehyde of $\leq 9.0 \mu \mathrm{g} / \mathrm{m}^{3}$. The estimated indoor air concentration of formaldehyde in an office with the MF sample was $54.4 \mu \mathrm{g} / \mathrm{m}^{3}$; the results for the soy, PUR, and dowel samples were all at or below $2.5 \mu \mathrm{g} / \mathrm{m}^{3}$.
\end{abstract}

Keywords: cross-laminated timber; adhesives; formaldehyde; polyurethane; soy; IAQ; VOCs

\section{Introduction}

The effects of the indoor air quality (IAQ) on human health have received an increasing amount of attention in recent years [1]. Poor IAQ can adversely impact physiological markers of health, such as respiratory ailments, the risk for allergies, chronic disorders, and cancer, and has been shown to negatively affect cognition [2-4]. IAQ can be affected by various sources, including chemicals, gases, volatile organic compounds (VOCs), and biological particulates, such as bacteria, fungi, and pollen [1,5]. Indoor environments consist of a mix of outdoor and indoor pollutants, with outdoor pollutants primarily entering through infiltration and mechanical ventilation systems and indoor pollutants originating from combustion sources, emissions from building materials and furnishings, and occupants $[1,2,6]$. IAQ is concerned with the air within buildings, regardless of whether the pollutant source originates indoors or outdoors; however, as buildings are becoming increasingly air-tight with better design and construction practices, it is becoming increasingly important to address indoor sourced pollutants [7,8]. As energy efficient building strategies are becoming commonplace, a lack of attention to building IAQ can result in those energy efficient building strategies impairing 
IAQ. For example, "outdoor air supply rates may be reduced in order to promote energy efficiency but without compensatory actions such as source control, this can increase concentration of pollutants indoors and reduce IAQ" [7,9]. Eliminating or minimizing the number and concentration of toxic species present in indoor environments is of key importance and a necessary first step towards preventing their emission. In particular, quantifying the contributions to IAQ from building materials is required.

IAQ remains largely unregulated around the globe [7]. Indoor air pollutant levels in the U.S. are typically several times to several hundred times higher than outdoor levels; consequently, indoor air exposure can account for over $90 \%$ of human exposure to pollutants $[7,8]$. While regulations addressing IAQ remain relatively sparse, several laws have been passed to curtail emissions from building materials and products. Proposition 65 in California set out to tackle this problem in 1986, by mitigating source pollution and requiring businesses to provide warnings about exposure to chemicals that have been found to cause cancer, birth defects, or reproductive harm, allowing citizens to make informed decisions about their exposure to these chemicals. This was accompanied by the Proposition 65 list, which is updated every year and now includes over 900 chemicals [10]. Regarding indoor environments, formaldehyde and carbon monoxide are the pollutants that have received the most attention in recent years [11]. Formaldehyde has both carcinogenic [12,13] and neurotoxic effects [14]. Greatly reducing or eliminating toxic species emitted from indoor sources such as building materials will result in improved IAQ [7]. Certifications for low-emitting products have become more prolific as governments across the world have tightened regulations on product emission standards following regulations set by the California Air Resources Board (CARB). Several regulatory bodies, both domestic and international, specify various testing standards that can be used to demonstrate compliance for product emissions to be approved for commercial use [15]. Other agencies look beyond product emissions and regulate indoor air concentrations of specific VOCs, using, for example, chronic, 8-h, and acute reference exposure levels. Indoor air concentration levels for formaldehyde are set by varying U.S. agencies and organizations, such as NIOSH, OEHHA, CDC, LEED, FEMA, CARB, and others. While efforts to improve IAQ are becoming more common, inadequate understandings of links between pollutant levels and their effects, both acute and chronic, have resulted in inconsistent guidance and regulations implemented by governments and agencies worldwide [7].

Cross-laminated timber (CLT) is increasing in popularity in North America due to the aesthetic and environmental appeal of the panelized engineered wood product [16]. CLT is fabricated with at least three alternating and orthogonal layers of graded sawn lumber and laminated with a structural adhesive [17]. Panels are typically bonded under pressure using cold-set adhesives, while thermoset adhesives used in thinner engineered wood products are far less common due to the difficulty and expense of using heat to cure the resins in thick CLT panels [18]. Hydraulic or vacuum presses are the most common, while some manufacturers use radio frequency presses to heat cure resins, such as melamine-urea-formaldehyde (MUF) [18]. Common adhesives used in the production of CLT include polyurethane-based adhesives (PUR), which constitute roughly $60 \%$ of the global market, and MUF, with a value of $24 \%$, followed by nails/screws at $9 \%$ and other lamination strategies making up the remainder [18]. Adhesives can vary by manufacturer; however, in the U.S., adhesive formulations need to be in accordance with the ANSI 405 adhesive standard for use in structural glue-laminated timber, meaning formulations can vary greatly, as long as they meet varying stress and boil tests stipulated by the standard [18-20]. Each of the predominant commercial adhesives pose their own potential health risks. Engineered wood products containing MUF, MF, and other adhesives have been shown to emit formaldehyde during both production and use [2,21]. Wood itself is known to naturally emit formaldehyde, and emission levels have been found to increase during its processing, with procedures that include drying, pressing, and thermal-hydrolysis in the treatment of pulp mill sludge; however, these emissions remain relatively low by occupational standards, are known to be impermanent, and rapidly decrease following these procedures [22]. Polyurethane-based materials, used in many building and furniture applications, potentially expose workers to toxic isocyanate 
compounds during production [23]. In addition, polyurethane-based materials have an elevated fire toxicity compared to other commonly used building materials, primarily due to a greater emission of hydrogen cyanide (HCN) [24,25]. Therefore, there are potential health concerns associated with the use of several commercially available adhesives.

It remains an open question whether a smaller quantity of adhesive used, relative to the amount of wood in CLT panels, and the overall exposed surface area relative to the space will have a meaningful effect on IAQ [26]. However, the development of an adhesive free of potentially toxic species would help to alleviate concerns over deleterious impacts on IAQ. Dr. Kaichang Li's team, at Oregon State University, developed a soy-based adhesive for use in thinner wood composite materials such as plywood [27-30]. The formaldehyde-free adhesive has led to dramatic reductions in emissions of toxic species during both the production and use of composite wood materials. This soy-based adhesive is thermoset, as is typical for thin wood composites, while CLT panels are produced using cold-set adhesives such as PUR or with radio frequency, as is the case with some manufacturers using MUF [18,31]. Dr. Li's team has recently modified the soy-based adhesive formulation to make a cold-set adhesive suitable for the production of CLT panels. A comparative analysis of the emissions from the newly formulated soy-based adhesive and current commercially available structural adhesives is necessary to avoid possible unforeseen negative impacts on IAQ resulting from its use.

\section{Materials and Methods}

To characterize VOC emissions from exposed CLT in an indoor environment, and to compare the impacts of adhesives used in the fabrication of CLT on IAQ, small-chamber testing at an accredited facility following a standardized method was employed to test the emissions from four CLT samples with different bonding types. The IAQ performance of the soy-based cold-set CLT adhesive was compared to two commercially-used cold-set CLT adhesives compliant with ANSI/APA PRG 320 (PUR and MF), and to a dowelled CLT sample that used no adhesive [17].

\subsection{Test Samples}

Four CLT samples were tested. All were from $105 \mathrm{~mm}$ thick, three-lamellae (3-lam) panels produced with Douglas-fir (DF) dimensional lumber sourced and graded (\#2,\#3) from the same mill. The outer lamella used \#2 DF and the inner lamella was \#3 DF, compliant with the minimum grade lumber required per PRG 320 [17,31]. Three of the CLT samples were cut from $610 \mathrm{~mm} \times 610 \mathrm{~mm}$ laboratory-produced, face-glued, and mechanically cold-pressed panels. One was bonded with a proprietary soy flour and magnesium oxide $(\mathrm{MgO})$ adhesive developed by $\mathrm{Dr}$. Li at Oregon State University (Corvallis, OR, USA), a second was bonded with a commercially available one-part polyurethane adhesive (PUR), and the third was assembled using $19 \mathrm{~mm}$ diameter beech dowels pressed in and using no adhesive.

A fourth sample was cut from a commercially-produced CLT panel that was fabricated approximately eight months prior to the other samples, and it was bonded with a two-part melamine formaldehyde (MF) adhesive. Two-part adhesives allow for potential variation in the ratio of the mixture at application [32], and this ratio can have an impact on formaldehyde emissions from the finished product due to unreacted formaldehyde in the bonded panels [33]. For this reason, a commercially-produced sample was essential and selected as most representative of the resultant VOC emissions from an MF-bonded CLT panel. Collecting a sample from a commercially-produced panel shortly after production, as was done for the laboratory-produced samples, would have provided a better comparative result; however, a production panel was unable to be sourced directly from the manufacturer at the specific time of this research. The adhesive type used in the commercial sample was confirmed to be MF, by identifying the absence of a $\mathrm{C}=\mathrm{O}$ bond using Fourier-transform infrared spectroscopy (FTIR) analysis conducted at the Center for Advanced Materials Characterization in Oregon (CAMCOR) at the University of Oregon (Eugene, OR, USA). 
All CLT test samples were cut down to $244 \mathrm{~mm} \times 140 \mathrm{~mm}$, with a single joint centered at each lamella (Figure 1). This proportion, positioning, and sizing of test samples allowed the linear joint length to board face area ratio to be representative of a much larger surface area of exposed CLT. It also met the exposed surface area to volume ratio for small-chamber testing, targeting test criteria representing conditions for a private office. A single outer lamella face area was left exposed during testing, wrapping all other sides with aluminum foil, and representing one common installed configuration, where the underside of a CLT floor or roof panel is left exposed as a finished ceiling [34]. Built configurations where more than a single surface in a space is comprised of exposed CLT or configurations where more than one side of a CLT panel are left exposed are also common; this sample and testing configuration should be considered a low estimate for those physical conditions with a greater CLT surface area to air volume ratio experiencing the same air exchange rate.

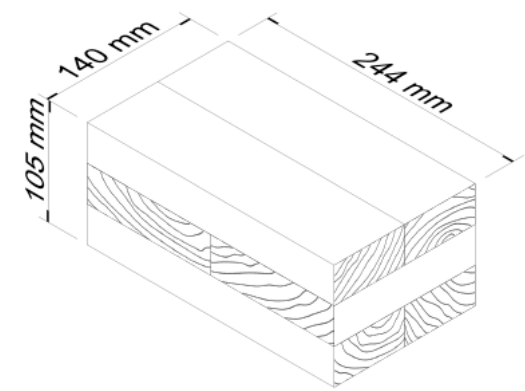

(a)

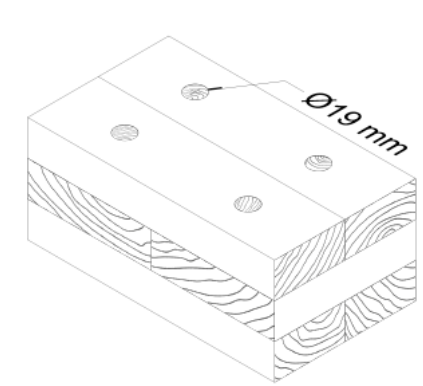

(b)

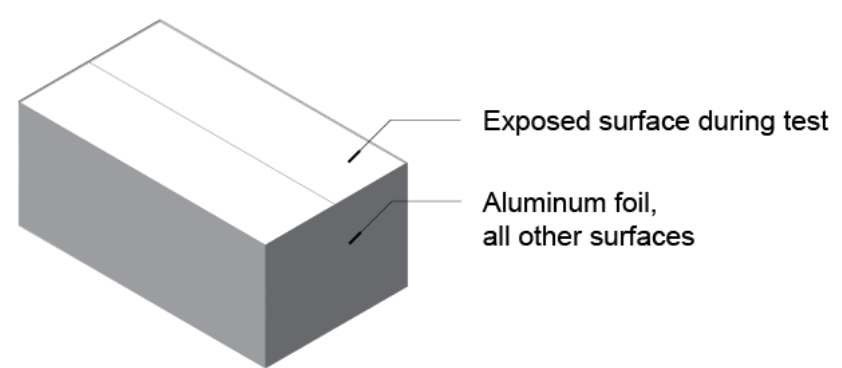

(c)

Figure 1. (a) Cross-laminated timber (CLT) sample dimensions. (b) Dowelled CLT sample assembled with four beech dowels. (c) Exposed surface area of samples during the test.

\subsection{Testing Laboratory}

Berkeley Analytical (Richmond, CA, USA) was selected to conduct small-chamber testing, as an internationally recognized and accredited facility under ISO/IEC 17020 since 2005 [35]. Berkeley Analytical, which is a $100 \%$ independent lab, has offered emissions testing since 1989, and as an accredited lab, has the authority to issue certificates of standard testing compliance [35,36]. Berkeley Analytical also works closely with the California Department of Public Health and the California Air Resource Board to make sure that the standards reflect and require the highest level of testing available [35]. This facility was chosen to provide clear and accurate product emissions data following standardized testing protocols.

\subsection{Small-Chamber Testing}

Evaluations of the IAQ impacts of CLT samples were carried out using the protocols outlined by the California Department of Public Health (CDPH) Standard Method for the Testing and Evaluation of Volatile Organic Chemical Emissions from Indoor Sources Using Environmental Chambers Version 1.2 [36]. The CDPH method was selected to obtain a full characterization of VOC emissions by species from each CLT sample tested and also follows the guidance of ASTM 
Standard D5116-06 and ISO 16000-9:2006 [36]. Under current California regulation, CLT is exempt from emissions testing as it falls under the classification of 'structural material' and does not need to be regulated as furniture or finishing material [37]. However, designers are regularly leaving CLT exposed for its aesthetic value, and even materials not exposed to the interior, such as batt insulation, have been shown to impact IAQ [38]. Evaluating indoor air VOC concentrations that result from exposed CLT and from CLT with different bonding types is useful for better understanding levels of compounds such as formaldehyde in CLT buildings and if they are anticipated to remain below the allowable indoor air concentration of $9 \mu \mathrm{g} / \mathrm{m}^{3}$ stipulated by the CDPH method and following the Chronic Reference Exposure Limit (CREL) adopted by the California Office of Environmental Health Hazard Assessment (Cal EPA/OEHHA) [36,39].

$\mathrm{CDPH}$ method test samples are procured as close to the date of production as possible, individually wrapped in aluminum foil, and sealed before being shipped to the test facility. At the test facility, samples are rewrapped in aluminum foil, this time exposing a single side of the sample, as it would be found in situ as an installed building product. Each sample is then placed in a conditioning environment for ten days, where the airflow, temperature, and humidity are maintained within the ranges shown in Table 1 and stipulated by California Specification 01350 [36]. At the end of the ten-day conditioning period, the sample is directly transferred to a small-scale chamber for a four-day testing period, adhering to more stringent airflow, temperature, and humidity criteria (Table 1 ). Air samples are collected from each chamber at 24, 48, and $96 \mathrm{~h}$ [36]. The 96-h sample represents emissions 14 days after a building product is installed, and in general, the earliest a building might be occupied after any given product installation. The test chamber used was $0.067 \mathrm{~m}^{3}$, with an average inlet gas flow rate of $0.067 \mathrm{~m}^{3} / \mathrm{h}$, achieving a loading ratio of $0.5 \mathrm{~m}^{2} / \mathrm{m}^{3}$.

Table 1. Small-chamber environmental testing conditions.

\begin{tabular}{ccc}
\hline Criteria & Conditioning Period & Test Period \\
\hline Duration & 10 days $\pm 5 \mathrm{~h}$ & 4 days $\pm 2 \mathrm{~h}$ \\
Temperature & $23^{\circ} \mathrm{C} \pm 2{ }^{\circ} \mathrm{C}$ & $23^{\circ} \mathrm{C} \pm 1{ }^{\circ} \mathrm{C}$ \\
Relative Humidity & $50 \% \pm 10 \%$ & $50 \% \pm 5 \%$ \\
Air Exchange Rate & $2 \mathrm{ACH}$ minimum & $1 \mathrm{ACH} \pm 0.05 \mathrm{ACH}$ \\
\hline
\end{tabular}

Chemical sampling and analyses followed U.S. EPA Compendium Method TO-17 and ASTM Standard Method D5197. Individual VOCs were collected in multisorbent tubes containing Tenax-TA backed by a carbonaceous sorbent, with low molecular weight aldehydes collected on treated 2,4-dinitrophenylhydrazine (DNPH) cartridges. VOC samples were analyzed using gas chromatography mass spectrometry (GC/MS), with formaldehyde and acetaldehyde analyzed by high performance liquid chromatography (HPLC). Formaldehyde and acetaldehyde were quantified using multi-point calibration curves prepared with pure standards. Other individual VOCs were also quantified in this manner when a pure standard was available or quantified using toluene as the calibration reference and based on their total-ion-current response.

\subsection{Estimated Indoor Air Concentrations}

After testing, the resultant chamber VOC concentrations were used to model estimated indoor air concentrations by space type [36]. The CDPH method defines typical space type criteria, including ventilation criteria based on ASHRAE Standard 62.1-2007 Ventilation for Acceptable Indoor Air Quality. Since the small-chamber test samples were sized such that the resultant chamber concentration would approximate the estimated indoor air concentration for the modeled scenario of a CLT ceiling in a private office, estimated indoor air concentrations were modeled and reported for this scenario. The IAQ modeling parameters are shown in Table 2. The test results are also valid for estimating indoor concentrations in school classrooms, though these values are not reported in this study. 
Table 2. Indoor air quality (IAQ) concentration modeling scenario parameters.

\begin{tabular}{ccc}
\hline Parameter & Units & Office Value \\
\hline Exposed product area & $\mathrm{m}^{2}$ & 11.1 \\
Room volume & $\mathrm{m}^{3}$ & 30.6 \\
Outdoor air flow rate & $\mathrm{m}^{3} / \mathrm{h}$ & 20.7 \\
Area-specific air flow rate & $\mathrm{m}^{3} / \mathrm{m}^{2}-\mathrm{h}$ & 1.86 \\
\hline
\end{tabular}

\section{Results}

All VOCs with emissions above the lower limit of quantification (LQ) from the exposed surface of CLT at the 96-h sampling time point are reported as estimated indoor air concentrations in a private office with an exposed CLT ceiling, as shown in Table 3. Target VOCs have allowable concentrations following the CDPH method and are one-half the CREL adopted by Cal EPA/OEHHA, except for formaldehyde, where the allowable concentration is the full CREL value of $9 \mu \mathrm{g} / \mathrm{m}^{3}[36,39]$. Only one VOC, for one of the four CLT samples, was found to have an estimated indoor air concentration above the allowable concentration. The aged CLT sample bonded with MF adhesive had an estimated indoor air concentration for formaldehyde of $54.4 \mu \mathrm{g} / \mathrm{m}^{3}$.

Table 3. Estimated indoor air concentrations of individual chemical compounds for a private office.

\begin{tabular}{|c|c|c|c|c|c|c|}
\hline \multirow{2}{*}{ Chemical } & \multirow{2}{*}{ CAS No. } & \multicolumn{4}{|c|}{ Estimated Office Indoor Air Concentration $\left(\mu \mathrm{g} / \mathrm{m}^{3}\right)$} & \multirow{2}{*}{$\begin{array}{l}\text { CDPH Method } \\
\text { Allowable Conc. }\left(\mu \mathrm{g} / \mathrm{m}^{3}\right)\end{array}$} \\
\hline & & Dowel & Soy & PUR & MF * & \\
\hline Formaldehyde & $50-00-0$ & 2.3 & 2.5 & 1.4 & 54.4 & 9 \\
\hline Acetaldehyde & $75-07-0$ & 7.1 & 4.5 & - & 5.0 & 70 \\
\hline Toluene & $108-88-3$ & 2.9 & - & - & - & 150 \\
\hline Acetic Acid & $64-19-7$ & 30.5 & 44.7 & 12.0 & 9.5 & - \\
\hline 2-Propanone (acetone) & $67-64-1$ & 12.6 & 2.8 & - & 2.3 & - \\
\hline Hexanal & $66-25-1$ & 24.5 & 11.7 & 4.2 & - & - \\
\hline Pentanal & $110-62-3$ & 4.1 & 2.1 & - & - & - \\
\hline 2-Furancarboxaldehyde (furfural) & $98-01-1$ & - & 4.6 & 3.7 & 3.9 & - \\
\hline (+/-)-alpha-Pinene & $80-56-8$ & 862.0 & 146.4 & 101.3 & 71.6 & - \\
\hline beta-Pinene & $127-91-3$ & 9.5 & 4.4 & - & - & - \\
\hline d-Limonene & $5989-27-5$ & 75.3 & 5.9 & - & 6.3 & - \\
\hline beta Myrcene & $123-35-3$ & 9.0 & - & - & - & - \\
\hline 3-Carene & 13466-78-9 & 10.4 & - & - & - & - \\
\hline p-Cymene & $99-87-6$ & 15.9 & - & - & - & - \\
\hline alpha-Terpineol & $10482-56-1$ & - & 2.3 & - & 2.4 & - \\
\hline Tricyclene & $508-32-7$ & 6.8 & - & - & - & - \\
\hline Camphene & $79-92-3$ & 7.4 & - & - & - & - \\
\hline$(+)$-Camphene & 5794-03-6 & 52.4 & - & - & - & - \\
\hline a-Phellandrene & $99-83-2$ & 2.2 & - & - & - & - \\
\hline beta-Phellandrene & $555-10-2$ & 2.9 & - & - & - & - \\
\hline $\begin{array}{l}\text { Benzene, 1-methyl-2-(1- } \\
\text { methylethyl)-; (o-cymene) }\end{array}$ & $527-84-4$ & 2.2 & - & - & - & - \\
\hline Dehydrosabinene & $36262-09-6$ & 4.0 & - & - & - & - \\
\hline Terpinolene & $586-62-9$ & 15.5 & - & - & 3.5 & - \\
\hline 1-Pentanol & $71-41-0$ & 2.4 & - & - & - & - \\
\hline p-(1 propenyl)-toluene & $104-46-1$ & 17.7 & - & - & - & - \\
\hline o-Isopropenyltoluene & $7399-49-7$ & 29.1 & - & - & - & - \\
\hline Triethylphosphate & $78-40-0$ & 2.1 & 2.1 & - & - & - \\
\hline Methyl acetate & $79-20-9$ & - & - & - & 23.8 & - \\
\hline $\begin{array}{l}\text { 2,2,4-Trimethyl-1,3-pentanediol } \\
\text { monoisobutyrate (Texanol) }\end{array}$ & $25265-77-4$ & - & - & 2.2 & - & - \\
\hline
\end{tabular}

* Melamine formaldehyde (MF) sample commercially-produced and aged eight months prior to testing.

\section{Discussion}

With CLT currently classified in California as a structural material, and thus being exempt from VOC emissions regulations, small-chamber testing was used to characterize the IAQ contribution and benchmark four bonding methods for structural mass timber panels. This is important since architects often choose to leave CLT exposed as an indoor finish material. Public awareness and government regulations have been increasing in recent years regarding VOCs in general, and specifically formaldehyde emissions from building materials, and their impact on IAQ and human health [40]. 
Limited data exist for formaldehyde emissions from CLT. The CLT Handbook, which is a popular industry resource, concludes that there was negligible or zero impact on IAQ from a five-sample study where all samples were bonded with a polyurethane adhesive [31].

Formaldehyde emissions for the CLT samples bonded with the soy-based adhesive and the commercially available PUR adhesive were low, with values of 2.5 and $1.4 \mu \mathrm{g} / \mathrm{m}^{3}$, respectively, and both were similar to the formaldehyde emissions from the dowel sample at $2.3 \mu \mathrm{g} / \mathrm{m}^{3}$. The value for formaldehyde emissions from the CLT sample bonded with MF adhesive was $54.4 \mu \mathrm{g} / \mathrm{m}^{3}$, which was significantly higher than the other three samples and six times higher than the CREL of $9 \mu \mathrm{g} / \mathrm{m}^{3}$ [36]. We estimated that a building constructed with this product would be unlikely to meet the LEED $\mathrm{v} 4$ air testing indoor air concentration maximum for formaldehyde of $33 \mu \mathrm{g} / \mathrm{m}^{3}(27 \mathrm{ppb})$, or the LEED v4.1 maximum concentration of $20 \mu \mathrm{g} / \mathrm{m}^{3}$ [41]. With LEED air testing being conducted after construction and prior to occupancy, it would be anticipated that the measured concentration at that time would be higher than was measured from the eight-month-old sample tested here [22]. Recommended and permissible exposure thresholds do vary, and the World Health Organization (WHO) has recommended-for a long time-a 30-min exposure limit of $100 \mu \mathrm{g} / \mathrm{m}^{3}$ for formaldehyde to prevent both short-term and long-term health effects [42]. Individual building products and interior finishes can be certified to aid in specifying and purchasing low-emitting products, and GREENGUARD Certification is one such program, with two tiers having different compliance criteria. To meet the GREENGUARD "Certified" tier for formaldehyde, the maximum allowable predicted concentration is $61.3 \mu \mathrm{g} / \mathrm{m}^{3}$ (50 ppb), and to meet the "Gold" tier, the limit aligns with the CDPH method at $9 \mu \mathrm{g} / \mathrm{m}^{3}$ (7.3 ppb) [43].

These findings, although rare, are not unexpected; in a 2002 study, Funch found a similar result when comparing the formaldehyde emission rate from a glue-laminated timber (GLT) sample bonded with a melamine urea formaldehyde (MUF) adhesive to those using other lamination strategies. Air samples taken at 10 days using small-chamber testing showed that the MUF sample had a formaldehyde concentration of $69 \mu \mathrm{g} / \mathrm{m}^{3}$, while the formaldehyde levels from a Phenol-Resorcinol-Formaldehyde (PRF) adhesive and a nail-laminated timber (NLT) sample were far lower, at 15 and $<10 \mu \mathrm{g} / \mathrm{m}^{3}$, respectively [44]. Formaldehyde has also been shown to persist in the indoor air of an occupied building constructed with CLT floor and roof panels, exposed as the finish ceiling, and supported by GLT columns and beams. Stenson et al. found a 30-min maximum formaldehyde concentration of $37 \mu \mathrm{g} / \mathrm{m}^{3}$ (30 ppb) in a ventilated and occupied open office space, and up to $77 \mu \mathrm{g} / \mathrm{m}^{3}$ (63 ppb) in an adjacent storage room with no mechanical ventilation, both at more than a year after construction [26]; however, explicit source tracking is difficult in occupied buildings.

The dowelled CLT sample had 14 VOCs not identified for the other three samples. Many of these were measured at levels near the lower limit of quantification (LQ); for example, toluene was reported at an estimated indoor air concentration of $2.9 \mu \mathrm{g} / \mathrm{m}^{3}$, far lower than the CREL of $300 \mu \mathrm{g} / \mathrm{m}^{3}$, or the allowable concentration of half that value. Additionally, (+/-)- $\alpha$-pinene is a terpene common to the oils of conifer trees like DF and was reported to be eight times the average emission rate of the other three samples; however, no allowable concentration exists for this compound. It is believed that the open nature of the lamellae in the dowelled sample, without adhesive to inhibit some of the emissions from the wood, resulted in greater emissions of several common VOCs that do not have a CREL compared to the other three samples laminated with adhesive. The four beech dowels are also unique to this sample, and it is possible that this may factor into the overall emissions profile of the dowelled sample, as different wood species do emit different VOCs [45].

The comparative VOC emissions analysis of CLT samples confirmed that the new soy-based adhesive performs well with respect to other commercially-used CLT adhesives, particularly for those VOCs where Cal EPA/OEHHA has adopted a CREL. Formaldehyde, acetaldehyde, and toluene were VOCs with a CREL identified in this study, and among the limited set of samples tested, the CLT sample bonded with the PUR adhesive was found to have the lowest concentrations-only emitting formaldehyde - and at the lowest rate of the samples tested. These small-chamber test results provide needed data to inform the selection of adhesives used in CLT fabrication and other engineered mass 
timber wood products for use in buildings as exposed interior finish material. Additional test results are needed to report VOC emissions from additional adhesive types, wood species, the impact of finishes, and indoor environment criteria to ensure healthy buildings for occupants through IAQ. CLT with MF adhesives warrant further testing to verify these results and to follow CDPH method guidelines more closely regarding the timeliness of sample collection and testing after production.

\section{Conclusions}

Adhesives used in the production of CLT present an important choice when fabricating this engineered wood product, and an opportunity for improved IAQ and occupant health when sourcing materials for use as primary and exposed structures in buildings. Some adhesives emit elevated levels of VOCs that are known to have deleterious impacts on human health, and other adhesives offer a more benign impact on a building's occupants through better IAQ.

In this study, VOC emissions from four Douglas-fir CLT samples were evaluated using small-chamber testing following the protocols of the CDPH method and estimated indoor air concentrations presented for a private office configuration with an exposed CLT ceiling. With the increasing popularity of structural mass timber buildings in North America as an alternative to concrete and steel structural systems, and with these exposed structural elements currently exempt from such testing requirements, these results are timely. The IAQ performance of a laboratory-produced CLT sample bonded with a new soy-based cold-set adhesive was compared to a laboratory-produced sample bonded with a commercially available polyurethane (PUR) adhesive, and to one using no adhesive and assembled with dowels. A fourth commercially-produced eight-month-old sample bonded with melamine formaldehyde (MF) adhesive was also tested. The test results for the three laboratory-produced samples demonstrated VOC emissions compliance with the reference standard. The commercially-produced, aged CLT sample bonded with MF adhesive did not meet the acceptance criterion for formaldehyde of $\leq 9.0 \mu \mathrm{g} / \mathrm{m}^{3}$. The estimated indoor air concentration of formaldehyde in an office with the MF sample was $54.4 \mu \mathrm{g} / \mathrm{m}^{3}$; the results for the soy, PUR, and dowel samples were all at or below $2.5 \mu \mathrm{g} / \mathrm{m}^{3}$.

Research is needed to support building design and construction decisions. With the growing interest in healthy and resilient buildings, and in response to climate change and global carbon emission reductions, building materials and construction methods are quickly evolving. Buildings account for $40 \%$ of the energy consumption in the U.S. [46], and high-performance envelope strategies and heating, ventilation, and air conditioning (HVAC) systems often reduce outdoor air exchange rates in buildings in an effort to reduce energy use. In turn, the VOCs emitted by materials indoors result in greater concentrations in indoor air than they would have in older, less air-tight buildings [7]. Embodied carbon from building materials and construction accounts for $11 \%$ of global greenhouse gas emissions [47], and the use of CLT in buildings has been touted as a way to sequester carbon and replace other materials with high carbon emissions during production. CLT also potentially adds a large source reservoir of VOC emissions that may persist over time in indoor air. These relationships and interactions between the built environment and materials must be considered and analyzed as building design and construction methods continue to evolve. Moreover, material VOC testing and disclosure expectations and requirements are increasing, and it is unlikely that exposed structural CLT will remain exempt from these standards and regulations, as it clearly contributes to IAQ.

Author Contributions: Conceptualization, K.V.D.W. and J.S.; methodology, J.S.; validation, J.S., K.V.D.W. and M.Y.; formal analysis, J.S., K.V.D.W. and M.Y.; investigation, M.Y., J.S. and M.D.; resources, J.S. and M.Y.; data curation, M.Y. and J.S.; writing-original draft preparation, M.Y. and M.D.; writing-review and editing, M.Y., J.S., M.D. and K.V.D.W.; visualization, M.Y. and J.S.; supervision, K.V.D.W.; project administration, J.S.; funding acquisition, K.V.D.W. All authors have read and agreed to the published version of the manuscript.

Funding: This research was funded by the U.S. Department of Agriculture's Agricultural Research Service [USDA ARS Agreement 58-0204-6-002]. 
Acknowledgments: The authors would like to acknowledge Kaichang Li and Jian Huang at Oregon State University for their work in the development of the soy-based adhesive and production of the laboratory produced panels, and Berkeley Analytical, for providing small-chamber testing services.

Conflicts of Interest: The authors declare no conflict of interest.

\section{References}

1. Cincinelli, A.; Martellini, T. Indoor air quality and health. Int. J. Environ. Res. Public Health 2017, $14,1286$. [CrossRef] [PubMed]

2. Brown, S.K. Chamber assessment of formaldehyde and VOC emissions from wood-based panels. Indoor Air 1999, 9, 209-215. [CrossRef] [PubMed]

3. Annesi-Maesano, I.; Baiz, N.; Banerjee, S.; Rudnai, P.; Rive, S.; SINPHONIE Group. Indoor air quality and sources in schools and related health effects. J. Toxicol. Environ. Health. Part B Crit. Rev. 2013, 16, 491-550. [CrossRef] [PubMed]

4. Allen, J.G.; MacNaughton, P.; Satish, U.; Santanam, S.; Vallarino, J.; Spengler, J.D. Associations of cognitive function scores with carbon dioxide, ventilation, and volatile organic compound exposures in office workers: A controlled exposure study of green and conventional office environments. Environ. Health Perspect. 2016, 124, 805-812. [CrossRef]

5. Dales, R.; Liu, L.; Wheeler, A.J.; Gilbert, N.L. Quality of indoor residential air and health. Can. Med Assoc. J. 2008, 179, 147-152. [CrossRef]

6. Bluyssen, P.M. Towards an integrative approach of improving indoor air quality. Build. Environ. 2009, 44, 1980-1989. [CrossRef]

7. Steinemann, A.; Wargocki, P.; Rismanchi, B. Ten questions concerning green buildings and indoor air quality. Build. Environ. 2017, 112, 351-358. [CrossRef]

8. US Environmental Protection Agency (US EPA). US EPA's 2008 Report on the Environment. 2008. Available online: https://www.epa.gov/report-environment/indoor-air-quality (accessed on 5 March 2020).

9. Langer, S.; Bekö, G.; Bloom, E.; Widheden, A.; Ekberg, L. Indoor air quality in passive and conventional new houses in Sweden. Build. Environ. 2015, 93, 92-100. [CrossRef]

10. OEHHA California Office of Environmental Health Hazard Assessment Proposition 65. 2020. Available online: https://oehha.ca.gov/proposition-65/about-proposition-65 (accessed on 10 March 2020).

11. Wei, W.; Ramalho, O.; Mandin, C. Indoor air quality requirements in green building certifications. Build. Environ. 2015, 92, 10-19. [CrossRef]

12. IARC Working Group on the Evaluation of Carcinogenic Risks to Humans. Formaldehyde, 2-butoxyethanol and 1-tert-butoxypropan-2-ol. IARC Monogr. Eval. Carcinog. Risks Hum. 2006, 88, 1-478. [PubMed]

13. Hauptmann, M.; Lubin, J.H.; Stewart, P.A.; Hayes, R.B.; Blair, A. Mortality from solid cancers among workers in formaldehyde industries. Am. J. Epidemiol. 2004, 159, 1117-1130. [CrossRef] [PubMed]

14. Songur, A.; Ozen, O.A.; Sarsilmaz, M. The toxic effects of formaldehyde on the nervous system. Rev. Environ. Contam. Toxicol. 2010, 203, 105-118. [CrossRef] [PubMed]

15. Ruffing, T.C.; Brown, N.R.; Smith, P.M. Review of United States and international formaldehyde emission regulations for interior wood composite panels. Wood Fiber Sci. 2011, 43, 21-31.

16. Mallo, M.F.L.; Espinoza, O. Awareness, perceptions and willingness to adopt Cross-Laminated Timber by the architecture community in the United States. J. Clean. Prod. 2015, 94, 198-210. [CrossRef]

17. APA-The Engineered Wood Association. Standard for Performance-Rated Cross Laminated Timber; ANSI/APA PRG 320; APA-The Engineered Wood Association: Tacoma, Washington, WA, USA, 2019.

18. Muszynski, L.; Hansen, E.; Fernando, S.; Schwarzmann, G.; Rainer, J. Insights into the global cross-laminated timber industry. BioProd. Bus. 2017. [CrossRef]

19. Brandner, R.; Flatscher, G.; Ringhofer, A.; Schickhofer, G.; Thiel, A. Cross laminated timber (CLT): Overview and development. Eur. J. Wood Wood Prod. 2016, 74, 331-351. [CrossRef]

20. APA-The Engineered Wood Association. Standard for Adhesives for Use in Structural Glued Laminated Timber; APA-The Engineered Wood Association: Tacoma, Washington, WA, USA, 2018.

21. Salthammer, T.; Mentese, S.; Marutzky, R. Formaldehyde in the indoor environment. Chem. Rev. 2010, 110, 2536-2572. [CrossRef] 
22. Salem, M.Z.; Böhm, M. Understanding of formaldehyde emissions from solid wood: An overview. BioResources 2013, 8, 4775-4790. [CrossRef]

23. Baur, X.; Marek, W.; Ammon, J.; Czuppon, A.B.; Marczynski, B.; Raulf-Heimsoth, M.; Roemmelt, H.; Fruhmann, G. Respiratory and other hazards of isocyanates. Int. Arch. Occup. Environ. Health 1994, 66, 141-152. [CrossRef]

24. Stec, A.A.; Hull, T.R. Assessment of the fire toxicity of building insulation materials. Energy Build. 2011, 43, 498-506. [CrossRef]

25. Blomqvist, P.; Hertzberg, T.; Tuovinen, H.; Arrhenius, K.; Rosell, L. Detailed determination of smoke gas contents using a small-scale controlled equivalence ratio tube furnace method. Fire Mater. Int. J. 2007, 31, 495-521. [CrossRef]

26. Stenson, J.; Ishaq, S.L.; Laguerre, A.; Loia, A.; MacCrone, G.; Mugabo, I.; Northcutt, D.; Riggio, M.; Barbosa, A.; Gall, E.T.; et al. Monitored indoor environmental quality of a mass timber office building: A case study. Buildings 2019, 9, 142. [CrossRef]

27. Li, K.; Peshkova, S.; Geng, X. Investigation of soy protein-Kymene®adhesive systems for wood composites. J. Am. Oil Chem. Soc. 2004, 81, 487-491. [CrossRef]

28. Huang, J.; Li, K. A new soy flour-based adhesive for making interior type II plywood. J. Am. Oil Chem. Soc. 2008, 85, 63-70. [CrossRef]

29. Jang, Y.; Li, K. An all-natural adhesive for bonding wood. J. Am. Oil Chem. Soc. 2015, 92, 431-438. [CrossRef]

30. Mousavi, S.Y.; Huang, J.; Li, K. Investigation of poly (glycidyl methacrylate-co-styrene) as a curing agent for soy-based wood adhesives. Int. J. Adhes. Adhes. 2018, 82, 67-71. [CrossRef]

31. Karacebeyli, E.; Douglas, B. CLT Handbook-US Edition; FPInnovations and Binational Softwood Lumber Council: Point-Claire, QC, Canada, 2013.

32. Pizzi, A. Melamine-formaldehyde adhesives. Handb. Adhes. Technol. 2003, 2. [CrossRef]

33. Dunky, M. Adhesives in the wood industry. Handb. Adhes. Technol. 2003, 2, 50.

34. Wood Works. Acoustically-Tested Mass Timber Assemblies. Wood Products Council. 2019. Available online: https://www.woodworks.org/wp-content/uploads/Acoustically-Tested-Mass-TimberAssemblies-WoodWorks.pdf (accessed on 15 February 2020).

35. Berkeley Analytical Associates. ISO/IEC 17025: 2005 Laboratory Accreditation. Berkeley Analytical. 2016. Available online: https://berkeleyanalytical.com/working-us/accreditation (accessed on 10 March 2020).

36. Smith, K.; Dooley, D.; Brown, E.J. Standard Method for the Testing and Evaluation of Volatile Organic Chemical Emissions from Indoor Sources Using Environmental Chambers Version 1.2; No. 01350; California Department of Public Health: Sacramento, CA, USA, 2017.

37. State of California. Airborne Toxic Control Measure to Reduce Formaldehyde Emissions from Composite Wood Products; Title 17 California Code of Regulations; State of California: Sacramento, CA, USA, 2007.

38. Chin, K.; Laguerre, A.; Ramasubramanian, P.; Pleshakov, D.; Stephens, B.; Gall, E.T. Emerging investigator series: Primary emissions, ozone reactivity, and byproduct emissions from building insulation materials. Environ. Sci. Process. Impacts 2019, 21, 1255-1267. [CrossRef]

39. OEHHA California Office of Environmental Health Hazard Assessment. OEHHA Acute, 8-hour and Chronic Reference Exposure Level (REL) Summary. 2020. Available online: https:/oehha.ca.gov/air/general-info/ oehha-acute-8-hour-and-chronic-reference-exposure-level-rel-summary (accessed on 16 October 2020).

40. Bernstein, J.A.; Alexis, N.; Bacchus, H.; Bernstein, I.L.; Fritz, P.; Horner, E.; Li, N.; Mason, S.; Nel, A.; Oullette, J.; et al. The health effects of nonindustrial indoor air pollution. J. Allergy Clin. Immunol. 2008, 121, 585-591. [CrossRef]

41. U.S. Green Building Council (USGBC). LEED Reference Guide for Building Design and Construction. 2019. Available online: https://www.usgbc.org/resources/leed-reference-guide-building-design-and-construction (accessed on 27 January 2020).

42. World Health Organization. WHO Guidelines for Indoor Air Quality: Selected Pollutants; WHO Regional Office for Europe: Copenhagen, Denmark, 2010.

43. Underwriters Laboratories (UL). GREENGUARD Certification Criteria for Building Products and Interior Finishes. Available online: https://www.ul.com/resources/ul-greenguard-certification-program (accessed on 8 October 2020).

44. Funch, L.W. Determination of Emissions from Solid Wood Elements; Danish Technology Institute: Arhus, Denmark, 2002. 
45. Risholm-Sundman, M.; Lundgren, M.; Vestin, E.; Herder, P. Emissions of acetic acid and other volatile organic compounds from different species of solid wood. Holz. Als. Roh. Und. Werkst. 1998, 56, 125-129. [CrossRef]

46. U.S. Energy Information Administration (EIA). Monthly Energy Review April 2020; No. DOE/EIA-0035; EIA: Washington, DC, USA, 2020.

47. International Energy Agency (IEA). Global Status Report for Buildings and Construction. 2019. Available online: https://www.unenvironment.org/resources/publication/2019-global-status-reportbuildings-and-construction-sector (accessed on 25 March 2020).

Publisher's Note: MDPI stays neutral with regard to jurisdictional claims in published maps and institutional affiliations.

(C) 2020 by the authors. Licensee MDPI, Basel, Switzerland. This article is an open access article distributed under the terms and conditions of the Creative Commons Attribution (CC BY) license (http://creativecommons.org/licenses/by/4.0/). 